I Universidade Federal de São Carlos, São Carlos, SP, Brasil

zinhotravis@gmail.com

https://orcid.org/oooo-0002-7295-6306

Renan Martins Pereira'

\title{
VELEJAR E DESCOBRIR: CONSIDERAÇÕES SOBRE VAQUEIROS, CORPOS E LEMBRANÇAS
}

Neste artigo, ${ }^{\mathrm{I}}$ meu objetivo é analisar a partir de narrativas contadas por 'vaqueiros de verdade'2 como suas relações com o corpo, os animais e a caatinga produzem memória e reputação social. Mais especificamente, observo como essas relações com o corpo, os animais e o território constroem e reproduzem o 'prestígio' e a reputação de senhores reconhecidos no sertão de Pernambuco como 'vaqueiros, vaqueiros mesmo': senhores hábeis na arte de capturar o gado na caatinga, mas também hábeis na arte da memória. Por um lado, 'homens do campo' que vivem, trabalham e labutam na fazenda de gado cuidando do rebanho próprio ou do patrão. Por outro, 'vaqueiros velhos' ou 'antigos vaqueiros' cujo 'prestígio', 'conhecimento' e 'experiência' os diferenciam de 'vaqueiros mais novos', 'vaqueiros de vaquejada', 'vaqueiros de festa', 'vaqueiros modernos'.

Além disso, demonstro que a exaltação de uma vida de sacrifícios e as tarefas concernentes ao ofício do vaqueiro resultam de diversas de suas práticas e de seus conhecimentos, mas também de sua habilidade retórica de narrar acontecimentos passados, protagonizados por humanos, animais e caatingas. A partir de uma narrativa que me foi concedida na primeira pesquisa de campo que realizei em Floresta (PE)3 entre fevereiro e maio de 20I6, dou ênfase etnográfica à habilidade retórica de Cláudio Correia, 'vaqueiro velho' cuja particularidade no modo de confeccionar oralmente suas experiências passadas - e, consequentemente, no modo de confeccionar a memória - expressa uma relação contínua entre o corpo do vaqueiro, os animais e o território. Para ser 
e se dizer vaqueiro, do seu ponto de vista, necessita-se de um corpo específico. Não se é vaqueiro de qualquer forma, a qualquer tempo, em qualquer lugar nem, aliás, com qualquer corpo. De sua perspectiva, nem toda pessoa pode 'ser vaqueiro'. Trata-se de uma 'profissão perigosa' que requer domínio sobre os animais e o território, mas também sobre o próprio corpo.

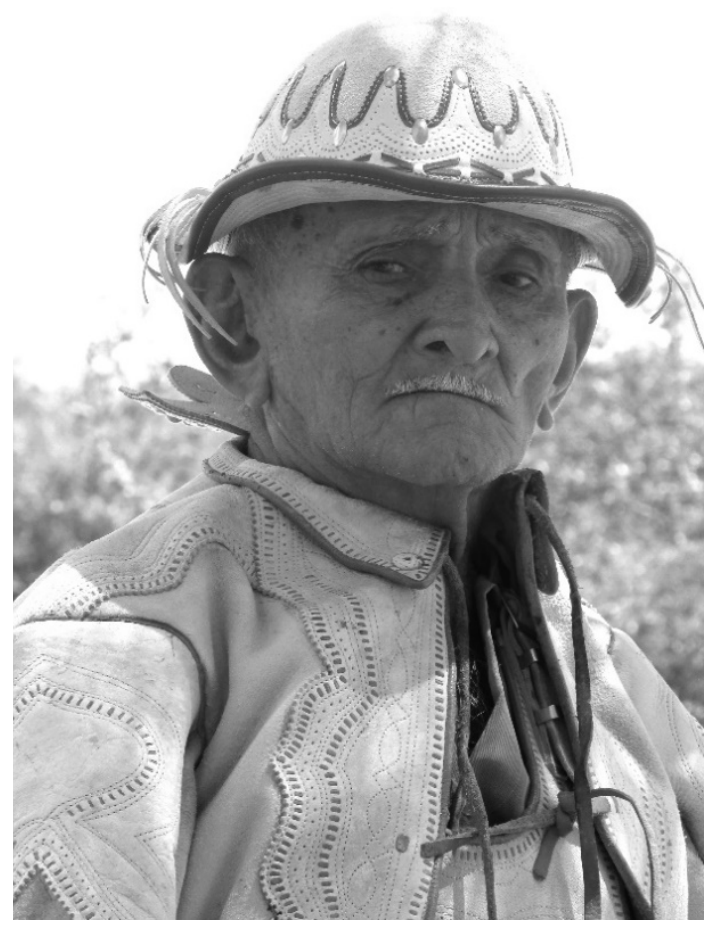

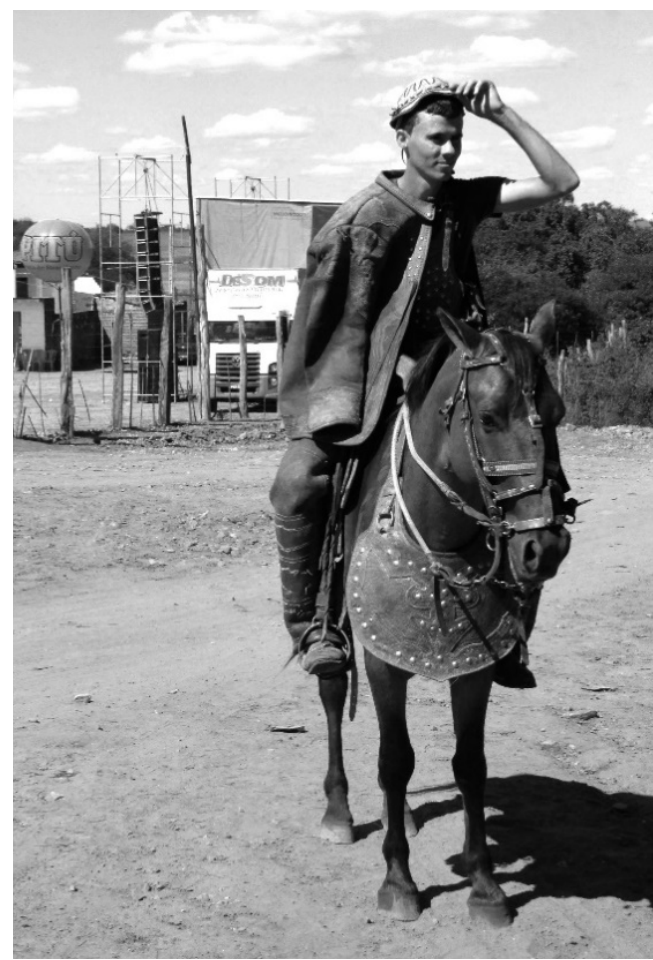

2

Figura I

'Vaqueiro véio' em sua propriedade,

Fazenda São Miguel (Serra Talhada-PE)

março, 2016

foto do autor

Figura 2

Jovem vaqueiro na 'vaquejada' da

Fazenda Lucas (Floresta-PE)

maio, 2016

foto do autor 
Metodologicamente, ' 'vaqueiros velhos' ou 'antigos' como Cláudio Correia e o senhor representado na Figura I são analiticamente importantes por três motivos. O primeiro deles é que detêm a sabedoria e a habilidade de narrar. Além disso, detêm a sabedoria e a habilidade de cavalgar. De um lado, trata-se da faculdade de falar a respeito de si (pensemos na imagem do narrador sentado no alpendre de sua morada reproduzindo relatos pessoais). De outro lado, trata-se da montaria, da cavalgada. Uma atividade obviamente definida pela mobilidade, pelo movimento, pela fuga do boi, pela corrida no 'mato's (pensemos na imagem do cavaleiro em movimento na caatinga). E, terceiro motivo, essas duas formas de sabedoria e habilidade (na posição de narradores e cavaleiros) produzem, juntas, memória e reputação: falar de suas aventuras na caatinga e ser hábil na arte da cavalaria são formas de os vaqueiros se perpetuarem no tempo, produzirem memória e deixarem um 'rastro'. Portanto, a predominância da narrativa de Cláudio Correia neste artigo se dá metodologicamente pelo seu modo particular de relatar o que ele considera momentos de glória: as 'pegas de boi' do passado e a 'vida de vaqueiro' no 'tempo dos antigos'.

Em antropologia, os trabalhos no Brasil sobre os sertões focalizam, em grande medida, a questão da memória na sua extensão com os temas, por exemplo, da mitologia nacional (Sena, I998, 20 I I), da narrativa (Lima, 2000; Cavignac, 2009), da política (Villela, 2008a, 2008b), da família (Marques, 2002, 2013) e do território (Godoi, I999). Poucos, porém, são os que se dedicam detidamente à figura do vaqueiro (Aires, 2008; Lopes, 2016; Pereira, 2017), mas ainda assim sem tratar das relações conjuntas dos vaqueiros com o corpo, os animais e o território na produção da memória, tal como desenvolvo neste artigo.

Ainda hoje prevalecem as teses de folcloristas (Cascudo, I956, 2005) e pensadores sociais brasileiros (Barroso, I930; Menezes, I970; Andrade, I986; Mello 20I I) a respeito do vaqueiro do Nordeste. Com a queda da pecuária nordestina no final do século XIX e início do XX, a previsão desses autores era a de que o vaqueiro e seu ofício desapareceriam da vida social sertaneja (Cascudo, I956, 2005; Prado Júnior, 2006; Furtado, 2007). O vaqueiro nordestino, no entanto, não desapareceu do meio rural. Não obstante os processos de "modernização" no campo, Lopes (20I6) e Pereira (20I7) demonstraram, recentemente, que a memória do vaqueiro permanece, transformando seus conhecimentos e suas práticas tradicionais.

Da prática da 'pega de boi', por exemplo, derivou a 'pega de boi no mato' ou 'pega de boi na caatinga'. Também chamada de 'vaquejada', a 'pega de boi' é um festejo nos sertões do Nordeste, onde um conjunto de vaqueiros - a 'vaqueirama' - disputa a derrubada do gado, visando à premiação e comemoração. 6 Quanto a essas competições, os 'vaqueiros de verdade' entre os quais realizei pesquisa de campo em Floresta são bastante críticos. Para eles, nas 'pegas de boi no mato' os vaqueiros lidam com o gado somente por lazer ou esporte. 'Antigamente', no entanto - eles afirmam -, as 'pegas de boi' eram atividade 
voltadas para as 'necessidades' do trabalho do homem rural. Para meus amigos sertanejos, as 'necessidades' concernentes às tarefas do vaqueiro se destinavam à manutenção e à vigília do rebanho. Uma vez que os trabalhadores se arriscavam na caatinga, o ofício do vaqueiro se fazia 'necessário', mas também prazeroso e gratificante, no sentido de que os desafios e perigos enfrentados na caatinga proporcionavam disputas e competições entre trabalhadores e fazendeiros, resultando algumas vezes em festejos, 'reuniões' e 'confraternizações'. A diferença é que nas 'vaquejadas' e nos desafios passados lidava-se com um rebanho selvagem e bravio. O gado era "criado solto na caatinga", era "bicho bruto que não via gente”. Hoje em dia, em contrapartida, dizem os vaqueiros, "o gado é manso, domesticado, preso em cercados e mangas". E, portanto, os cavaleiros já não são habilidosos e corajosos como os de antes.

Frente a essas diferenciações temporais, as lembranças, as memórias e as histórias passadas são constantemente agenciadas pelos vaqueiros de Floresta. Por essa razão, nas seções seguintes analiso como a relação dos vaqueiros com o corpo, os animais e a caatinga possibilita entender os procedimentos pelos quais os vaqueiros qualificam e diferenciam passado e presente, reverenciando-se como herdeiros de um tempo glorioso. A primeira seção é dedicada à questão do corpo. A segunda, aos animais e à caatinga. A terceira analisa a produção do 'prestígio' em sua correlação com a memória. As duas últimas seções procuram definir conceitualmente a memória do ponto de vista dos vaqueiros. Para tanto, faço uma análise da noção nativa de 'ciência do vaqueiro' a partir da noção grega de métis, tal como definida por Détienne e Vernant (2008).

\section{O CORPO}

Nos diálogos que estabeleci com os vaqueiros em Pernambuco, muito se dizia do desgaste físico e corporal vivido por eles em tempos remotos. Em um de meus encontros com Cláudio Correia, minha anfitriã em Floresta, Amélia, perguntou-lhe:

- Quer dizer que não podia sentir sede no mato?

- Sentia sede, claro. Mas não podia levar água para o campo. Não dava para beber nem comer, porque não podia carregar nada na sela - respondeu-lhe sem delongas.

- Mas por quê? - perguntei-lhe.

- Ué, porque é incômodo! - afirmou com obviedade.

'Campo' significa a parte não cercada da caatinga, território livre para os animais, onde nasce e vive o rebanho, "solto no mato", que em certos períodos necessita ser recrutado para fins de manutenção e vigília de vaqueiros e "criadores'.7 Sua forma verbal 'campear' é sinônimo de 'descobrir' na espacialidade específica do 'campo' as reses (gado bovino) e as 'criações' (gado caprino e ovino) de um rebanho. ${ }^{8}$ 
Para procurar e capturar as reses, os vaqueiros devem, por exemplo, alimentar-se comedidamente, ser frugais e moderados. Uma carne de bode assada na brasa - comum entre os alimentos dos sertanejos - não é uma boa opção. "Para correr na caatinga atrás de um boi", reflete Cláudio, "deve-se comer algo leve". Primeiro, para não despertar a fome durante a cavalgada. Em segundo lugar, para que a sede não se antecipe antes da hora. Em síntese, o trabalho do vaqueiro exige uma economia do corpo. Uma forma de regê-lo, preveni-lo e prepará-lo.

"Antigamente", disse o interlocutor, "o vaqueiro saía de madrugada atrás de uma rês". Nessa circunstância, segundo ele, reinam os imprevistos. Não se sabia de antemão, por exemplo, a que horas vaqueiro e cavalo (e quem sabe o boi) retornariam do 'mato'. Na vida do vaqueiro, as tarefas nem sempre são findadas como se espera. Mesmo capturado, o gado pode deixá-lo à sorte do destino. "O vaqueiro pode pelejar para sair com o boi e ele não sair". O gado pode lutar para não se submeter às ordens do homem. Ele resiste à morte, assim como o homem também se adestra contra ela. Nesse sentido, sofrer mas ao mesmo tempo preservar-se e ter cuidado de si são atitudes essenciais de quem enfrenta os perigos da caatinga e as surpresas do destino.

Cláudio me contou ter arriscado a própria vida capturando um determinado boi. Nos anos I970, ele e um 'companheiro' saíram às três da manhã para pegá-lo, encontraram-no às três da tarde e só terminaram de amarrá-lo às sete da noite. Passaram o dia todo sem comer e sem beber água. Ao chegar a casa, o vaqueiro se encontrava completamente "arrebentado, enfadado e doído”. O ‘sofrimento' era tanto, que, embora necessitasse de água, o corpo a rejeitava: "Os lábios eram rachados, e eu não conseguia engolir nada, só café amargo". Apesar do 'sofrimento' (ou talvez em virtude dele), meu amigo lembrava do ocorrido com bastante orgulho. Afinal de contas, asseverou: "Essa é a realidade do vaqueiro do campo", o solo onde o vaqueiro cultiva o seu 'prestígio'.

Muitos 'vaqueiros velhos' de Floresta adquiriram reputação por já ter dormido no 'mato' à espera de um boi ou por passar horas sem se alimentar. Por esses e outros motivos, 'vaqueiros velhos' se articulam retoricamente para nos convencer de que sofreram mais do que ninguém. Para eles, os 'vaqueiros mais novos' jamais se submeteriam a condições equivalentes. E isso não diz respeito apenas a um problema moral e geracional. Acontece que os motivos são de natureza prática: embora se digam vaqueiros, os 'mais novos' não vivem, não sofrem e não se dedicam à 'profissão de vaqueiros' como os de 'antigamente'. Pode-se notar, portanto, a partir da lógica do 'sofrimento' elaborada por Cláudio Correia, apenas uma primeira demonstração de como a memória é trabalhada e construída nas narrativas a partir das relações com o corpo, os animais e o território, de modo que a produção do 'prestígio' e da reputação social só ocorre à medida que essas relações existam e façam sentido.

Mas qual o saldo do 'sofrimento'? Por que o vaqueiro é devoto ao exercício de sua 'profissão' a ponto de, em seu nome, sacrificar-se horas ou dias na 
caatinga? Seria supostamente em nome de uma tarefa a partir da qual se firmam compromissos com alguém a quem se deve o boi prometido, um cliente ou um patrão, e, além do mais, em nome de um compromisso vital do vaqueiro de si para consigo? Sob o sol escaldante e à espera da rês prometida, o vaqueiro se esgota até finalmente capturá-la. Os corpos precisam ser ágeis, sobretudo para adquirir velocidade na 'carreira' - ato em disparada atrás do gado. Nas palavras de Genésio de Nato, vaqueiro da Fazenda Lucas, não se trata apenas de 'sofrimento', mas também de 'agilidade'. Para ele, os vaqueiros não correm no 'campo' somente para honrar um 'trato', seja com o cliente, com o fazendeiro ou consigo mesmo. E também não o fazem apenas para cuidar do rebanho. Sobretudo, fazem-no por uma questão de 'agilidade', uma vez que os objetivos estão condicionados às relações com os animais e o território. Em suas palavras, "O vaqueiro tem que saber a luta do mato!".

Dessa maneira, ao mesmo tempo em que se trata de responsabilidade moral, de uma questão de 'honra' ou 'prestígio', sugiro que se trata igualmente de um problema técnico e pragmático - sobre isso, exatamente, trato melhor na última seção deste artigo, em que abordo a categoria 'ciência do vaqueiro'. Trata-se, enfim, da percepção do que é e do que não é eficiente na 'luta do mato'. No lugar de comidas e bebidas, como bem nos demonstrou Cláudio Correia, prevalecem ferramentas e utensílios. Na indumentária e nos arreios, carregam-se 'peias' (cordas para amarrar os animais e imobilizá-los), 'serrotes' (para cortar as 'pontas' dos bois quando pontiagudas), 'caretas' (máscara de botar na rês para interromper o poder da visão) e 'búzios' (instrumento de sopro feito com a 'ponta' do boi com o qual os homens se comunicam, principalmente para avisar aos 'companheiros' a aproximação dos animais).

Encourado, com os acessórios essenciais e sem carregar comida e bebida nos arreios, o vaqueiro do sertão, segundo Cláudio Correia e Genésio de Nato, dá primazia à atitude de 'correr limpo'. Segundo eles próprios, a leveza na montaria é o que dá velocidade, ritmo e, portanto, 'agilidade' aos corpos. Ela implica a possível vitória na captura, isto é, os domínios dos homens sobre os animais frente aos imprevistos, perigos e desafios. Tendo em vista o modo como as técnicas e as habilidades se desenrolam na 'luta do mato', na seção seguinte trato de analisar como a memória do vaqueiro é produzida nos relatos não apenas a partir de suas relações com o corpo, mas também das relações com os animais e a caatinga.

\section{OS ANIMAIS E A CAATINGA}

Em nossas conversas, Cláudio sempre enfatizava a função do cavalo na 'carreira'. A esse respeito, mencionou que o vaqueiro não é nada sem um 'bom cavalo'. Tal a sua importância na corrida que, orgulhoso de si mesmo, destacou suas posses: 
- Eu já tive cinco cavalos de 'campo', só para correr atrás de boi, só para 'campear'! - e, exaltado ao se lembrar do passado, deu início a uma narrativa. - Vou te contar uma 'história de vaqueiro'! Aconteceu que um dia eu fui para o 'campo' pegar um boi, um determinado boi...

Nesse exato dia, o vaqueiro mencionou que estava só. Ao lembrar da árdua tarefa a ser cumprida, passou na fazenda de seu tio, Manoel Gomes Correia, também conhecido como Nelinho Yoyô. Ao encontrá-lo, disse ao parente: "Padinho, me dê um empregado para me ajudar a pegar um boi, pra eu não ir só?”. Acompanhado, Cláudio e seu 'companheiro' seguiram.

Nesta fase da narrativa, os olhos do vaqueiro-narrador reviviam o passado. Enquanto falava, seus gestos pareciam refletir suas lembranças:

- Meu amigo, vou te dizer uma coisa: a gente achou esse boi num lugar meio fechado, onde havia muita macambira, muito espinho. A caatinga era 'braba' e, de repente, o gado se espantou de longe. E correu, correu. Fugiu!

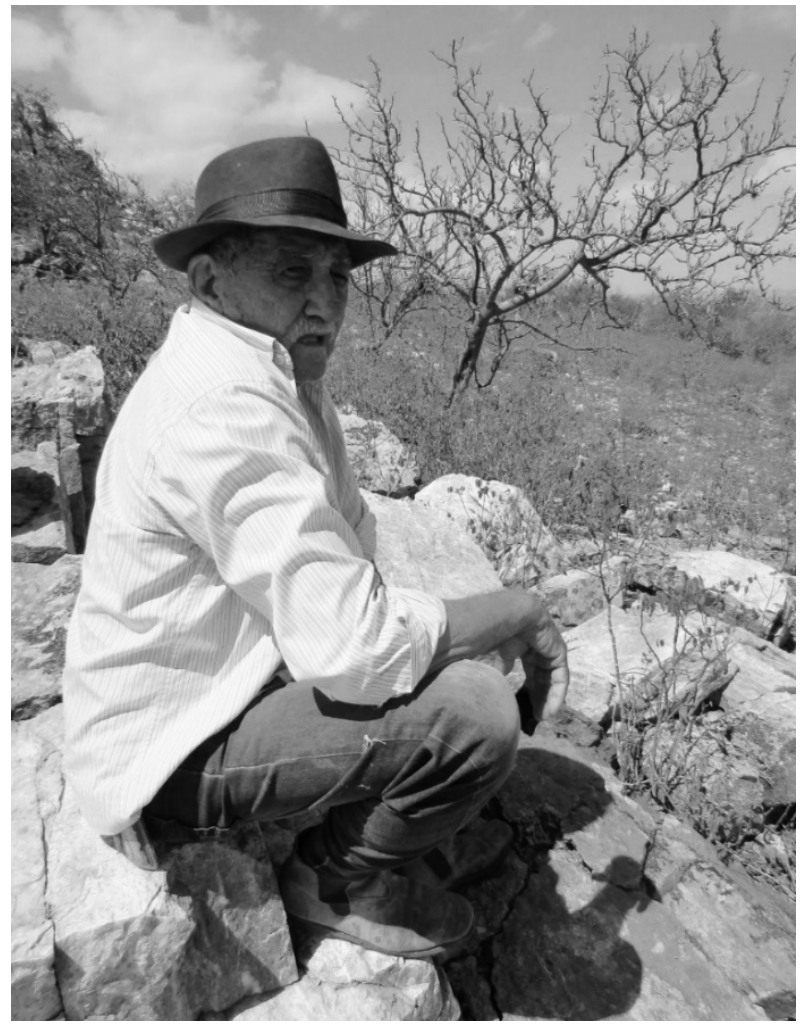

Figura 3

Cláudio Correia na Fazenda Tigre (Floresta-PE)

abril, 2016

foto do autor 
Nesse momento, portanto, o alvo começou a fuga, dando início à primeira 'carreira'. Segundo os vaqueiros, o boi se espanta porque sente 'medo'. De antemão, o gado não expressa 'valentia', pois o seu temor é a reação imediata de quem se depara com seres externos ao seu convívio. Para Dulcimar, vaqueiro de Cláudio, "o gado brabo que a gente cria tem medo". Criado na caatinga à própria sorte, o gado 'brabo' é definido como "bicho bruto que não vê gente”. Outros animais, no entanto, "já são valentes por natureza". O primeiro foge. Já os últimos, a depender das circunstâncias, podem enfrentar o homem que, entretanto, tem vantagem sobre o boi só e despreparado, pego de surpresa. O boi, então, é vítima das circunstâncias, enquanto seu oponente está devidamente prontificado. Ao gado resta a própria fuga, fomentando a fúria de quem virá em seu encalço. O boi, aliás, é quem confere ritmo e duração à corrida. Seguindo o 'rastro' do gado, é preciso que o vaqueiro vá ao seu encontro, tentando descobri-lo. Em seguida, tendo-o feito, é preciso 'puxar' o cavalo para cima dele, ir de encontro a ele, para tocá-lo, puxá-lo pela cauda, derrubá-lo, capturá-lo.

Cláudio continuou:

- Eu puxei no cavalo, descobri onde o boi ia e tirei o cavalo em cima. Eu ia descendo de cabeça baixa. Olha, você sabe a posição que o vaqueiro corre no 'campo', não sabe? - perguntou-me, supondo que com os poucos dias em Floresta eu talvez soubesse a resposta.

Para correr no 'campo', descrevia o vaqueiro, é preciso o olhar atento de quem iguala o seu corpo ao do cavalo, apoiando-se no seu pescoço. A caatinga é cortante e tortuosa, e nela o vaqueiro precisa da visão aguçada. Em uma caatinga 'fechada', por exemplo, é preciso potencializá-la. Se a visão aguçada é condição para o 'vaqueiro do campo', é porque aos olhos do vaqueiro somam-se os olhos do cavalo. O encaixe de um corpo ao outro complementa a capacidade coletiva de manter a atenção e o movimento - na próxima seção, volto com mais afinco à importância da visão na corrida. Por ora, antes de retornar à narrativa de Cláudio, faço breve digressão sobre a postura corporal do vaqueiro na corrida.

Segundo os vaqueiros de Floresta, ao compartilhar o movimento e produzir ritmos variados, cavaleiro, cavalo e boi se harmonizam até a hora de uma ruptura, o fim da corrida. Nesse contexto, há um jogo de confiança e disputa entre os seres. O cavalo, por exemplo, é o veículo por excelência do vaqueiro. Com ele, os homens atingem a velocidade do boi sob determinada modulação ecológica: a caatinga espinhosa e cortante. Se levarmos a sério a ideia de Deleuze e Guattari de que "o corpo não é questão de objetos parciais, mas de velocidades diferentes” (201 2: 42), podemos dizer que a busca pela leveza na montaria e a atitude de 'correr limpo', já mencionadas por Cláudio, dependem da relação entre corpos de naturezas distintas, humanas e não humanas.

Sob esse aspecto, as características da vegetação e dos animais contribuem para a particularidade do ofício do vaqueiro. Quanto mais penosa a caatinga, maior a reputação humana. Quem souber lidar com a braveza e a va- 
lentia do gado em determinado ambiente ganha maior 'prestígio' e mais reputação, diferenciando-se de seus pares. Aos vaqueiros são conferidos atributos específicos, a saber: 'catingueiro', 'estragado de mato', 'valente', 'bom vaqueiro', 'cabra corajoso', 'doido'. Mas a vegetação - que se imaginaria única e invariável - também se distingue em categorias específicas segundo seus próprios atributos. Conforme os perigos que impõe e a natureza dos animais que nela vivem, a caatinga é dividida em duas mais notórias: 'caatinga de tabuleiro' (com vegetação rasteira, 'aberta' e, por isso mesmo, facilitadora da técnica de 'descobrir' o rebanho) e 'caatinga fechada' (chamada também de 'caatinga braba' - espaço épico onde se luta com o gado bravio e selvagem).

o quadro geral é que, na posição de cavaleiro, os 'vaqueiros de verdade' se aventuram geralmente na 'caatinga braba' procurando dominá-la, uma vez que ela tem suas parcelas de passividade como plano de circulação e de passagem. Sendo 'braba', 'fechada', 'espinhosa', 'tortuosa', cortante e, portanto, desafiadora, ela é também, entretanto, um obstáculo a ser contornado, um plano de circulação e de passagem que, conforme a aceleração da corrida, pode interromper a velocidade, o ritmo, a frequência. Um ecossistema que atinge, perfura e mata. A esse respeito, Cláudio Correia oferece com sua narrativa algumas pistas:

- Depois de 'descobrir' o boi, encontramos uma 'vereda' dentro de um 'macambiral'. E o boi tanto 'buracou' nessa 'vereda', que eu botei o cavalo nesse bicho e saí curtinho com ele.

Nesse instante, ele explicava que seu corpo permanecia rente ao pescoço do cavalo. Ele e seu cavalo estavam próximos do boi. Enquanto se preparava para derrubá-lo, o inesperado aconteceu. Numa curva da 'vereda', 'descobriu' uma árvore, um pé de angico que "nascia da beira do caminhozinho e fazia um galho". A passagem era estreita e, segundo ele, "o galho vinha em cima". O vaqueiro desviou do galho. No ritmo da fuga, segundo o vaqueiro, "o boi parecia que se abaixou pra passar". Destacando a sagacidade do boi e as decisões feitas por ele, o narrador ressaltou um problema. Embora os corpos estivessem rentes, a altura do cavalo com a do cavaleiro prejudicava a travessia. Para resolvê-lo, Cláudio disse não ter tido tempo para "pensar no que fazer". De sua perspectiva, não houve lugar para contemplação:

- Eu não tive tempo de me levantar pra pensar. Se eu me levantasse, o pau me matava. Não podia levantar, senão eu quebrava a cabeça. O boi entrou, o cavalinho entrou e eu também.

Frente ao obstáculo, ele percebeu a ineficiência de se manter apoiado no pescoço do cavalo. Buscando apoio lateral, conquistou outra posição. Reutilizando os corpos, produziu uma nova frequência. Da divisão rítmica entre cavaleiro e cavalo, surgiu um movimento diferencial, um gesto mínimo e totalmente inovador. Um desvio. 
- Eu tirei o corpo da sela... - disse o vaqueiro encenando a maneira pela qual se apoiou lateralmente em seu cavalo para conquistar uma nova posição. O arranjo necessário para atravessar.

Para ele, embora o galho fosse um obstáculo imposto pelo boi, entre os dois grandes aliados, cavalo e cavaleiro, há também uma relação de disputa. Segundo sua narrativa, homem, cavalo e boi não podem ser pensados separadamente. O cavalo seguirá sempre o que o boi faz. "O boi entrou, e o cavalinho entrou também!". Nessas circunstâncias, cabe ao homem acompanhar a fuga, o movimento iniciado pelo boi. E cabe a ele também saber sustentá-lo ou, quem sabe, transformá-lo, obtendo um desvio. O cavalo segue incondicionalmente a trajetória do boi; impedi-lo é um erro. Talvez uma fatalidade. Se o boi engana, levando o cavalo a um caminho perigoso, o cavalo é vulnerável às armadilhas assim como o cavaleiro o é. Nas corridas, as vidas dividem os mesmos riscos. Traçando os mesmos rumos, o boi procura fugir, esconder-se, enquanto cavaleiro e cavalo o perseguem, desejando descobri-lo a todo custo.

"Eu passei só com 'isso aqui' em cima do cavalo!", Cláudio asseverou apontando para sua coxa direita. Para ele, todos estavam no limite. Boi, homem e cavalo estavam, segundo o narrador, "na conta de passar". Em fração de segundos, o cálculo foi espontâneo e imediato, produzindo um movimento sequencial: esticar-se no pescoço do cavalo; mudar de posição diante do imprevisto (um galho!); e, por fim, apoiar-se lateralmente. Essas atitudes trouxeram sua primeira vitória. Adiante, um novo desafio: derrubar e 'dominar' o boi. $\mathrm{Pa}$ ra tanto, onde estava seu 'companheiro'? A seguir, trato da técnica de 'correr junto' e do 'prestígio' envolvido nesse empreendimento.

\section{O PRESTÍGIO}

Nas 'pegas de boi', geralmente não há lugar para que dois vaqueiros tenham protagonismo, pois sempre haverá apenas um vencedor. Há o que correrá 'na ponta', e outro que seguirá por trás, acompanhando dois movimentos sequenciais: o trajeto traçado pelo vaqueiro que corre 'na ponta' e que supostamente derrubará o boi, puxando-o pela cauda ou pulando em seu pescoço; e as subsequentes rotas e desvios feitos pelo gado durante o percurso.

“Quando eu estava 'piando', chegou o companheiro." Em geral, 'piar' significa "dominar o boi". Detalhadamente, é quando a rês, para ser tangida, terá suas 'mãos' (patas) e 'pontas' (chifres) amarradas umas às outras. Cláudio, porém, não precisou da ajuda de seu parceiro. No limite entre a vida e a morte, passar sob o galho potencializou a atitude de terminar a empreitada sozinho. Mais uma fonte de atuação magistral do 'vaqueiro do campo', do 'vaqueiro de verdade': realizar autonomamente o que em teoria deveria ser feito em coletivo. Não se trata, contudo, de escolhas e vontades. Trata-se, sobretudo, de 'necessidade' e obviedade. Como já vimos, nas corridas não há lugar para hesitações, simples escolhas ou contemplações. Independentemente de o 'compa- 
nheiro' estar atrasado ou não, é preciso 'lutar' com o gado antes que retome o fôlego, ganhe energia e parta. Os imprevistos não são meros obstáculos, mas elementos que catalisam as disputas, segmentam as continuidades e traçam novos desafios. Logo, correr ao lado de alguém não é só um meio de subtrair os perigos e compartilhá-los. Não se trata somente de cumprir o 'trato' com o cliente ou o patrão. Não é só uma fonte de reciprocidade, correlação e 'honra', mas também de unilateralidade, parcialidade e disputa.

Ora, se um único vaqueiro triunfará, é porque esse será o protagonista de um acontecimento extraordinário, e o parceiro, embora coadjuvante, atestará o desafio vencido pelo outro. Por isso, o ‘companheiro' não é só o olho que procura o boi e segue o curso dos movimentos. Ele é também o olho-testemunha. É o campo de visão que comprova o que o outro foi capaz de fazer. A esse respeito, vejamos o que disse Cláudio do 'companheiro' que testemunhou o fato:

No final, o companheiro chegou e me disse: "Meu amigo, como você passou naquele pau?". "Ué", eu respondi, "não sei, só sei que eu passei". Na hora, não me chamou muito a atenção, porque eu sou acostumado a fazer isso: passar e pronto. Mas, enfim, pegamos o boi e fomos embora. Só que o rapaz insistiu na altura do pau. Ele disse: "Óia, ali onde você passou é muito baixo, o negócio lá é muito apertado". Eu disse de volta: "É, eu sei que é muito baixo, eu abaixei tudo o que pude e tirei o corpo de cima da sela, porque senão eu quebrava o espinhaço ou então a cabeça. Eu poderia morrer".

No dia posterior ao acontecimento, ele decidiu revisitar o palco de sua façanha. No pé de angico, estava a prova. O 'rastro' era a casca de árvore saltada, descolada do tronco, demarcando a passagem, a rápida colisão, o parcial atrito que atingiu apenas a coxa direita do cavaleiro.

- Eu senti mesmo que roçou o pau na perna... É por isso que tirou a casca do angico! - refletiu meu amigo nos instantes finais de sua narrativa.

Por onde passou, chamou-lhe atenção a altura entre o galho e o solo. Ele, então, mediu para ver quantos palmos davam. O cavalo tinha seis palmos e meio, a contar a espessura da sela. Do chão até o pau, a medida foi de cinco palmos e meio, e o cavalo tinha um palmo a mais. Ora, o vaqueiro atravessou um espaço menor que o tamanho do seu 'animal'. Sem hesitar, logo constatou a destreza do cavalo. $\mathrm{O}$ aliado em quem um dia confiou e a quem agora deve a 'honra' de uma 'história'.

- Quer dizer, o cavalo diminuiu um palmo para passar, se abaixou e me salvou! Se não fosse um cavalo bom... Enfim, mesmo se fosse um vaqueiro bom e um cavalo ruim, o cavalo tinha me matado na hora, e o boi tinha ido embora.

É em razão dessa mutualidade de sentimentos, habilidades e perigos que os vaqueiros valorizam a montaria. Cascudo (I956: 75), por exemplo, percebeu que desde o ciclo do gado "o animal favorito não é o touro, o novilho, a vaca, o boi, mas o cavalo". O seu significado maior, segundo a perspectiva de meus in- 
terlocutores, é que o cavalo não defende apenas a si mesmo. Como fiel escudeiro, ele defende também o seu aliado. Percebe-se a partir disso que a dimensão do extraordinário contida nas 'histórias de vaqueiro' não se fundamenta apenas nas intenções do boi, mas em um "agenciamento coletivo" (Deleuze \& Guattari, 2008), nesse caso, no agenciamento cavaleiro-boi-cavalo-caatinga. ${ }^{9}$

Como destacado na narrativa de Cláudio, para controlar o tempo e tomar as decisões corretas, não há espaço para contemplação, e as ações em nada se confundem com um cálculo racional. Em vez disso, as relações dos homens com os animais e a caatinga se desenrolam segundo os agenciamentos entre eles. Trata-se de relações entre humanos e não humanos que não são teleológicas, isto é, equacionadas por causas e efeitos, mas de natureza tautológica, isto é, faz-se o que deve ser feito. Nas palavras de Cláudio: "A gente não pode pensar que vai morrer ou que não vai morrer. Isso é coisa que o vaqueiro tem que fazer, simplesmente fazer!".

Minha amiga Amélia, bastante curiosa, perguntou-lhe por que motivo, no momento do perigo, não desistiu daquela 'vereda' perigosa. Se tudo era arriscado demais, pensou minha amiga, por que ele não estacionou o movimento e escolheu outra trajetória? Diante da provocação, a resposta do vaqueiro foi clara: "Sim, existe a possibilidade. Mas o ponto é que, se desistirmos, o boi vai embora." A desistência, portanto, não é a solução. No limite, se o que está em jogo é o próprio 'prestígio' do vaqueiro, deixar o boi fugir quando se está tão próximo dele é nada mais que uma ação imprudente e 'covarde'. O correto é sempre fazer o que o boi faz. Na corrida, o homem segue o boi justamente porque o cavalo tem um mandato: "O cavalo entra da maneira que o boi entrar, senão também morre!” asseverou Cláudio diante das indagações de Amélia.

Os argumentos do vaqueiro sugerem que a desistência é uma alternativa ainda mais perigosa, botando em risco a vida do cavalo que cumpre o seu papel. Portanto, manter-se no ritmo da 'carreira' é, a despeito do que possa acontecer, respeitar quem o carrega. Não fariam sentido saudar o 'sofrimento', as horas sob o sol escaldante e se reverenciar como 'vaqueiro de verdade' se todo imprevisto, toda dificuldade ou qualquer obstáculo cedessem lugar à desistência. Desistir, portanto, mais do que um ato 'covarde', é uma atitude ineficaz.

No lugar da desistência, a permanência. Em vez da redução, a aceleração. Entre permanências e acelerações, o vaqueiro sabe que se há desvios e decisões a tomar elas são internas aos próprios movimentos, às continuidades e aos cruzamentos. Para entender melhor essas questões, é fundamental analisar outra habilidade do 'vaqueiro do campo': antes da 'carreira' (aceleração, fuga e colisão), vem o ato de 'velejar' (vagarosidade, procura e atenção). 


\section{VELEJAR E DESCOBRIR: POTENCIALIDADES DO CORPO}

Até onde pude compreender, 'velejar' significa aguçar a percepção visual e auditiva, potencializando o corpo do vaqueiro na busca pelo boi. Em movimento vagaroso, a finalidade de 'velejar' é 'descobrir' o animal que se esconde. 'Velejar' é também sinônimo do que, às vezes, os vaqueiros chamam de 'caçar'. De uma forma ou de outra, trata-se de processos em que os sentidos do vaqueirocaçador se adestram para 'descobrir' a presa-gado que vigia o homem, mas também é vigiada por ele. 'Velejar' é, enfim, 'descobrir' o 'gado brabo' que teme o seu adversário.

Além da visão e da audição, joga-se também com os odores. O 'cheiro' do vaqueiro encourado é atenuante. O boi foge ao senti-lo. Por isso, com a devida astúcia, o vaqueiro deve 'velejar' contra o vento. Ao contrário do barco à vela que se utiliza do vento para ganhar sentido e velocidade, o vaqueiro corre contra o vento de modo que o 'cheiro' do couro não dê pistas de sua proximidade. O vento para o navegante é um combustível; para o vaqueiro, um obstáculo. A respeito dos sentidos, foi Dulcimar quem destacou a importância do olfato e da audição:

O gado sente o cheiro, eu não entendo, é o cheiro da gente que eles pegam. Óia, se eu tiver nessa posição aqui [segundo ele, a favor do vento], o gado sente e corre. Agora, para ele não sentir, a gente tem que ir contra o vento, abaixado, devagarzinho e desviando dos paus pra não quebrar e pra não fazer barulho, porque se fizer barulho, o boi também corre.

A visão aguçada, o controle do ar e o silêncio são meios para obter êxito quando o vaqueiro procura o boi que se esconde. É por essas e outras razões que os vaqueiros reduzem as ações do boi em algum momento atingindo-o justamente nos olhos. Se capturado, vendam-lhe os olhos com a 'careta', tipo de máscara feita de couro.

Segundo meus interlocutores, vendar os olhos é uma forma de 'dominar', mas também de jogar com o animal. A venda é uma das vantagens que os cavaleiros têm em relação à 'presa'. Embora o corpo do cavaleiro esteja devidamente protegido pela indumentária (couro que transmite 'cheiro'), seus olhos estão totalmente descobertos (e por isso, é claro, ele vem a 'descobrir' o que está à sua frente). Ao passo que a visão é potencializada, os olhos, contudo, se tornam a superfície mais vulnerável, pois facilmente atingida por algum espinho, por uma ponta de galho, pela caatinga cortante e tortuosa.

Nessas circunstâncias, é comum vaqueiros ficarem cegos. Dois vaqueiros de Floresta, Quinca Pedro e Dulcimar de Canãa, perderam a visão 'campeando'. O primeiro ficou cego de um olho, mas persistiu por um algum tempo. Ao ficar cego do outro, o 'rei dos vaqueiros' - como ainda é conhecido o finado Quinca Pedro - abandonou definitivamente a 'profissão'. Sua história, no entanto, permanece. Biografias foram escritas sobre ele (Ferraz, 2004), e missas ainda são celebradas em sua homenagem. 


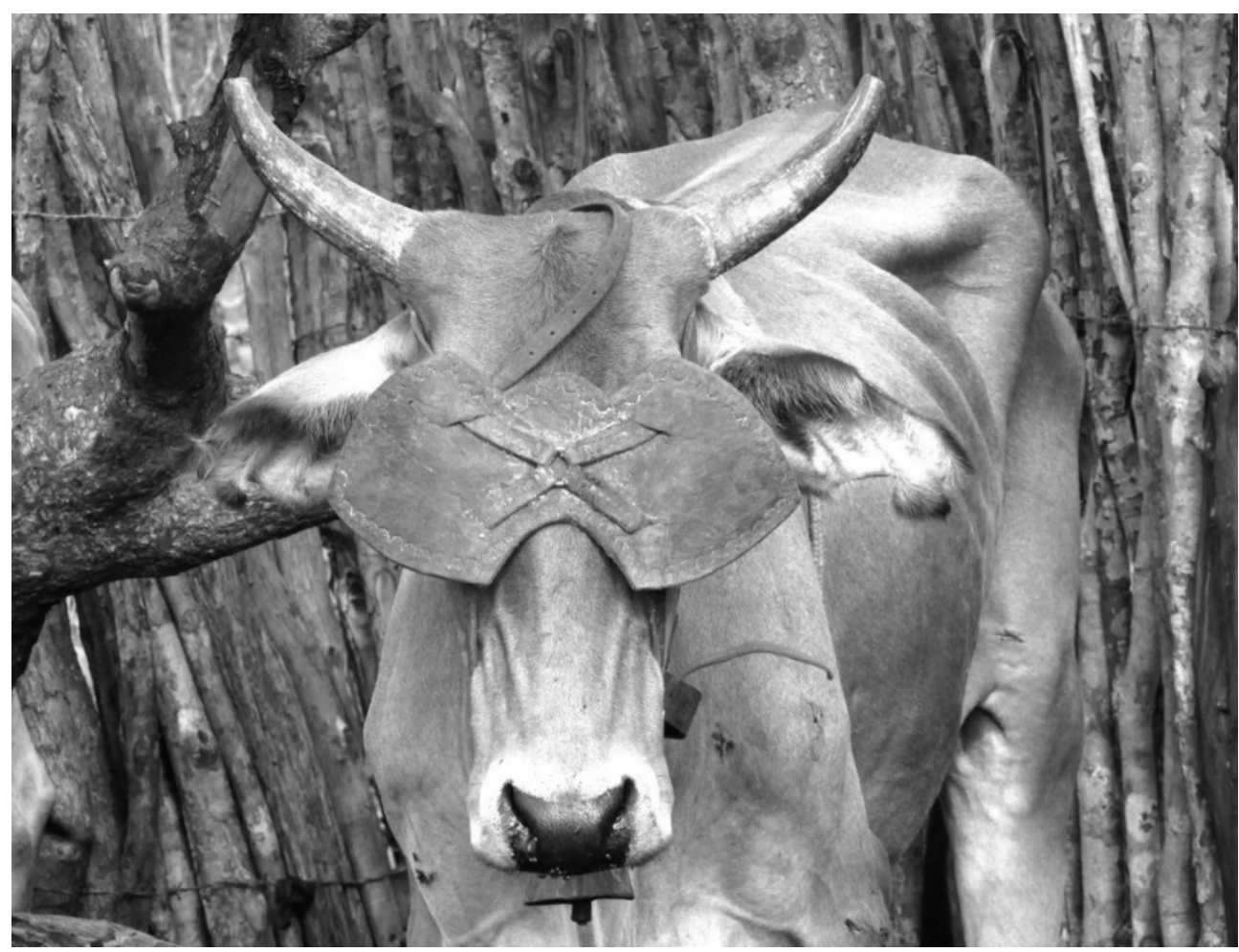

Figura 4

Boi 'encaretado'; 'pega de boi' na

Fazenda São Pedro (Floresta-PE)

fevereiro, 2016

foto do autor

O segundo vaqueiro, Dulcimar, no momento em que o conheci, tinha perfurado o olho esquerdo, e, embora estivesse parcialmente recuperado, já não suportava o sol. A visão impotente e afetada pela claridade fez do 'campo' e das 'vaquejadas' práticas cada vez menos frequentes em seu cotidiano. $\mathrm{O}$ vaqueiro, porém, deixou sua marca. Na Serra Negra, onde a caatinga é 'braba' e a mata é fechada, Dulcimar pegou um boi 'afamado' e 'valente', Marroeiro, o animal que lhe concedeu 'fama' e 'prestígio'.

Em virtude da memória, a percepção enfraquecida, a anulação do corpo e a consequente desatenção à vida são situações que vaqueiro nenhum deseja. Para meus interlocutores, o cavaleiro cego é praticamente a morte; porém, embora a cegueira e a morte levem à anulação de uma prática, elas não trazem o seu esquecimento. Para não ser esquecidos e anulados, o objetivo dos vaqueiros passa a ser exatamente a construção da memória. Quanto mais experiente e vivido o vaqueiro, mais 'história' carregará consigo e provavelmente dele se 
falará e se lembrará. Daí a importância de 'vaqueiros velhos' e 'antigos'. Daí, enfim, a importância do corpo, dos animais e do território no processo de construção da memória, do 'prestígio' e da reputação dos homens.

Mas, afinal, que memória é essa que os vaqueiros buscam a todo instante recorrer e reconstituir de modo a garantir o seu 'prestígio'? A seguir, analiso o modo como o 'conhecimento' e a 'experiência' dos vaqueiros extrapolam o campo conceitual da antropologia e das ciências sociais no que se refere à memória e às categorias a ela adjacentes.

\section{CIÊNCIA DO VAQUEIRO}

Os relatos trazidos por Cláudio Correia neste artigo seguem o propósito de conservar uma verdade histórica. Do fenômeno narrado surge, por exemplo, um conselho. Ele reelabora um momento pretérito e transmite uma verdade aos seus ouvintes. Concluindo definitivamente a sua narrativa, disse-me: "Tudo isso que eu te contei, meu amigo, é a 'ciência do vaqueiro'!".

Sabe-se bem que a memória é um objeto de conhecimento complexo e controverso no campo das ciências humanas e sociais. Ela envolve um debate interdisciplinar, associando-se, portanto, a diversos conceitos, termos e temáticas. Sob a clássica perspectiva dos "quadros sociais da memória", a sociologia francesa buscou dar conta de uma "memória coletiva", diretamente conectada às noções de sociedade e Estado-nação (Halbwacks, I994, I 997). Na historiografia, a memória recebeu interpretações e relativizações variadas da noção de "tempo histórico". Nessa linha, as teses produzidas na Escola dos Anais são célebres no que diz respeito aos métodos para lidar com a memória coletiva (Bloch, I925) e a sua relação com a história (Le Goff, 2003). Preocupados mais com os processos de memorização do que necessariamente com os conteúdos da memória, o historiador Pierre Nora e o filósofo Paul Ricouer propuseram conceitos importantes para o debate. O primeiro se concentra na categoria de "lugares de memória", a fim de entender por meio dela as representações materiais e imateriais do espaço na memória coletiva (Nora, I989). O segundo propõe o conceito de "memória justa", segundo o princípio de que recordar é em si mesmo um ato relacional, uma forma de alteridade (Ricoeur, 2000). No que se refere à relação entre memória e alteridade, Fabian (20I3) sugere que, se os estudos a respeito da memória social no campo da história se debruçam sobre o passado, a função da antropologia é lidar com as comunidades no presente, tomando o passado não como uma totalidade em si, mas um conjunto de temporalidades e espacialidades culturalmente definidas. É em torno do debate de como as sociedades lembram, esquecem e recompõem o seu passado (Douglas, I986; Connerton, I989) que os pós-colonialistas e os pós-modernos, no contexto de uma disputa epistemológica nos anos I 980 entre memórias oficiais e memórias subalternas (Pollak, I989), buscaram analisar como a história é mobilizada na vida cotidiana e, ademais, quais os limites do passado 
como recurso para a produção da memória (Appadurai, I98I). Entretanto, devido à profusão terminológica e semântica da noção e aos seus usos nos mais diferentes eixos temáticos e perspectivas de análise nas ciências humanas, Berliner (2005) sugere que a memória é frequentemente confundida com os objetos, os conceitos e as temáticas a ela correlatos, entre eles, principalmente: sociedade, cultura e identidade.

Este artigo trata de uma memória que dê conta especificamente das relações dos vaqueiros com o corpo e, mais ainda, da interespecificidade entre humanos e animais, pois o 'vaqueiro de verdade' só constrói memória e pode conquistar o seu devido 'prestígio' se as 'histórias' contadas por ele derem aos ouvintes um conjunto de gestos e imagens em que homens, animais e caatingas estejam entrelaçados.

Para Walter Benjamin (I987: I98), por exemplo, a "arte de narrar" é "a faculdade de intercambiar experiências". Nesse sentido, os "vaqueiros de verdade' podem ser pensados, nesse caso, como sábios narradores cujas funções são as de compartilhar o que viveram para transmitir, segundo Joana Medrado (20I 2: I59) em seu estudo sobre os vaqueiros na Bahia, "os valores que as histórias veiculam". Ainda segundo Benjamim (I987: 200), a experiência vivida e narrada resulta sempre "num ensinamento moral, numa sugestão prática, num provérbio ou numa norma de vida". Tendo eficiência, preparo e disciplina (não levar comida e bebida para o 'campo', por exemplo), o vaqueiro expõe a sua sabedoria. Mas se a sabedoria é "o lado épico da verdade", como quer Benjamin (I987: 200), o que há de épico nas 'histórias de vaqueiro' está justamente na conjunção da 'experiência' com o 'conhecimento', no que Cláudio nomeou 'ciência do vaqueiro'.

Mas essa conjunção 'experiência-conhecimento' como 'ciência do vaqueiro' não é sinônimo de erudição ou de objetividade. Por essa via, a 'ciência do vaqueiro' está longe de estabilizar saberes e leis que normatizem os fatos - além de transmitir conselhos, ensina aos ouvintes o que o cavaleiro sabe, o que pratica e como o pratica. Não está em jogo, portanto, somente compartilhar conhecimentos e experiências, mas também expor uma forma específica de sabedoria.

Ao modo da métis grega, sugiro que a 'ciência do vaqueiro' é o efeito de "formas de inteligência astuciosa" (Détienne \& Vernant, 2008: 2I). Para os autores, o homem dotado de métis "está sempre prestes a saltar [...] ao agir no tempo de um relâmpago".

Isto não quer dizer que ele cede, como fazem comumente os heróis homéricos, a um impulso súbito. Ao contrário, sua métis soube pacientemente esperar que se produzisse a ocasião esperada. Mesmo quando ela procede de um impulso brusco, a obra da métis situa-se nos antípodas da impulsividade. A métis é rápida, pronta como a ocasião que ela deve apreender no voo, sem deixá-la passar [...]. Em vez de flutuar lá e cá ao sabor das circunstâncias, ela ancora profundamen- 
te o espírito no projeto que ela maquinou antes, graças a sua capacidade de prever, além do presente imediato, um pedaço mais ou menos espesso do futuro (Détienne \& Vernant, 2008: 21-22).

As práticas dos vaqueiros se assemelhariam nesse sentido às atividades do artesão grego e do guerreiro homérico. Como abordado por Détienne e Vernant, as formas de conhecimento desses oficiais clássicos não são objetivas, mas processuais, concretizando-se concomitantemente à transformação da experiência vivida.

Como vimos na narrativa de Cláudio Correia, o saldo das ações do cavaleiro provém da minimização dos erros e, sobretudo, da prudência frente aos imprevistos. Para Detiénne e Vernant (2008: I7), "a capacidade inteligente que a métis designa se exerce sobre os planos mais diversos, mas sempre onde o acento é posto sobre a eficácia prática, a procura do êxito em um domínio da ação". Por conta da imprevisibilidade e dos domínios acionados, algo se supõe à custa do que se aprendeu em vias de antecipar o futuro pela memória. Em face da natureza intempestiva dos acontecimentos, a 'ciência do vaqueiro' não se articula por códigos e regras, e os narradores não darão a seus ouvintes uma sequência ordenada (e cronológica) de fatos sociais. Em suas epopeias, o vaqueiro é um memorialista, e sua 'ciência' funciona segundo a conservação e a acumulação do passado no presente. A 'ciência do vaqueiro' pode ser, portanto, uma sabedoria que gera conselhos (Benjamin, I987), um tipo de inteligência astuciosa (Détienne \& Vernant, 2008) e, ao mesmo tempo, uma forma muito específica de memória. Pela materialidade da "memória", segundo o filósofo Henri Bergson (2009: 5), os homens se ocupam "do que existe e do que vai existir".

Ora, como vimos até agora, as 'histórias' contadas pelos vaqueiros são, por um lado, prévias do que o cavaleiro é capaz de fazer e, por outro, uma análise de suas ações frente às incertezas do tempo. Suas narrativas reconstroem os fenômenos passados à medida que os desenrolam no presente com o intuito de dar ao narrador a oportunidade de contar o que realmente sabe. Parafraseando JeanPierre Vernant (I978: 45), "bom dizedor de casos porque bom fazedor de feitos".

Não se trata, contudo, de viver para lembrar e de lembrar para narrar. Se as relações dos vaqueiros com o corpo, os animais e a caatinga se entrelaçam de maneira contínua em seus relatos é porque os vaqueiros buscam constantemente produzir memória a fim de evitar o esquecimento e, ademais, para conquistar 'prestígio' e reputação. Eternizadas, porém, as lembranças extravasam o corpo de quem as carrega. Elas necessitam se expandir e correr no mundo. Cravam-se em outros corpos, nos animais, nas folhas, na terra, no tronco das árvores, nos homens, nos couros que os revestem. Com os 'rastros' deixados no tempo e no espaço, o vaqueiro do sertão edifica a sua verdade histórica. 


\section{CONSIDERAÇÕES FINAIS}

Neste artigo, desenvolvi uma correlação temática pouco explorada na literatura antropológica sobre os sertões do Nordeste, a saber: corpo, memória e relação humano/animal. Primeiramente, demonstrei que a reputação do vaqueiro é resultado de relações particulares com o 'sofrimento', os animais e a caatinga. Em seguida, com o objetivo de analisar a natureza dessas relações na prática da 'pega de boi', empenhei-me para entendê-las segundo os conteúdos da narrativa de um interlocutor reconhecido em Floresta como 'vaqueiro de verdade'. Nos relatos desse vaqueiro, homens e animais estão propensos a tomar ritmos diferentes na corrida. Como vimos, o ato de 'velejar' não é apenas procurar o que se esconde, mas ganhar velocidade e, por conseguinte, transformarse na 'carreira', substituindo a vagarosidade, a procura e a atenção por aceleração, fuga e colisão. No ato de 'velejar', dá-se mais energia aos olhos e à busca do boi. Na 'carreira', por sua vez, a fuga do boi põe os corpos em disputa.

Concluo que se na corrida o vaqueiro arrisca a própria vida é porque as 'pegas de boi' são espaços privilegiados de atualização e construção da memória. Nos limites de seu ofício (como a cegueira e a anulação do corpo), mediante a produção da memória o vaqueiro constrói para si um modo de vida caracterizado pelo 'sofrimento' e pela 'honra' (o compromisso com o cliente, consigo mesmo, com o parceiro e com o cavalo), mas também pela 'agilidade', pelo 'conhecimento' e pela 'experiência'. Nesse sentido, a disposição dos corpos no território e os rumos traçados pelo cavaleiro, como entendi, não são a consequência de meras escolhas, equacionados por uma relação de causa e efeito, mas fruto de uma forma particular de inteligência - a 'ciência do vaqueiro'.

Por fim, sugiro nesta conclusão que o vaqueiro não é apenas uma imagem que se perpetua no tempo, uma tradição, um resquício histórico. Mais especificamente, o vaqueiro do sertão é uma memória cujo poder está na ação e na transformação do corpo. Primeiro, vimos que o cavaleiro se move, corre atrás de um boi e se arrisca na caatinga. Depois, vimos que a sua faculdade de recordar o torna um memorialista (aquele que lembra, narra e registra os próprios feitos). Agora, vê-se que a possibilidade de ser recordado o transforma em monumento (aquele de quem se lembra, fala e escreve).

Recebido em 20/I2/20I8 | Revisto em I7/9/20I9 | Aprovado em I/IO/20I9 
Renan Martins Pereira é mestre pelo PPGAS/UFSCar e atualmente doutorando no mesmo programa (bolsista Capes), com estágio de doutorado sanduíche na UC Davis. Pesquisador integrado ao Hybris (Grupo de Estudo e Pesquisa sobre Relações de Poder, Conflitos, Socialidades) e ao NuAP (Núcleo de Antropologia da Política). Realiza pesquisa de campo no sertão de Pernambuco desde 2016. Seus principais temas são memória, ecologia, relação humano/ animal e teoria antropológica; e as principais publicações, "Dominação e confiança: vaqueiros e animais nas pegas de boi do sertão de Pernambuco"; "Cavaleiros em tempos de glória: uma análise etnográfica da história do vaqueiro do Nordeste"; "O sertão, a seca e o fim". 


\section{NOTAS}

I Agradeço primeiramente aos meus amigos e às minhas amigas sertanejas que tão bem me acolheram em Floresta. Este artigo é dedicado a eles/as - uma pena que a pandemia tenha nos afastado fisicamente, por ora. Agradeço as leituras atentas e generosas de Jorge Villela e Ana Claudia Marques de suas primeiras versões, assim como aos colegas do Hybris, grupo de pesquisa (UFSCar/USP) em que pude compartilhar algumas das primeiras ideias que aqui se encontram. Também não poderia deixar de agradecer aos debatedores do GT "Práticas Esportivas e Corporalidades" Carlos Eduardo Costa e Yasmine Ávila Ramos, que contribuíram com críticas e sugestões pertinentes à versão prototípica deste artigo quando de sua apresentação no IV Seminário de Antropologia da UFSCar em 2017. Agradeço ainda aos pareceristas anônimos pelos comentários, críticas e sugestões, assim como à equipe editorial da revista Sociologia \& Antropologia por todo o suporte técnico. Por fim, agradeço à Capes pelo financiamento.

2 Termos entre aspas simples correspondem a expressões nativas. Frases entre aspas duplas representam transcrições diretas da fala nativa e citações de autores acompanhadas de referência bibliográfica.

3 O município de Floresta está localizado sertão de Pernambuco, mais especificamente, na mesorregião do São Francisco e na microrregião do sertão de Itaparica, distante $439 \mathrm{~km}$ da capital do estado, Recife. Segundo dados de 2016 do IBGE, sua população estimada é de 32.I52 habitantes.

4 Os recursos metodológicos utilizados no trabalho de campo para coleta de dados (entre eles, em grande parte, narrativas e histórias contados por 'vaqueiros de verdade') foram os mais variados: anotações no caderno de campo, mas sobretudo e preferencialmente material de áudio (com gravador) e de audiovisual (com câmera fotográfica digital). Não cabe aqui neste artigo, por falta de espaço e por não ser seu objetivo, desenvolver um debate sobre o assunto, contudo ficam como referência bibliográfica alguns trabalhos que elaboram metodologicamente discussões específicas no campo da antropologia visual (Collier, I973; Rouch, 2003; Sztutman, 2005), parte deles mobilizando uma relação entre memória e imagem (Koury, 200I; 
Severi, 20Io), a partir de intermediação de pesquisador, câmera e objeto na escrita etnográfica.

5 'Mato', especificamente nesse contexto, refere-se à área de caatinga, longe da 'morada', do quintal, das cercas (currais e mangas). Em outros casos, 'mato' se opõe também à 'rua', nome que se dá à zona urbana.

6 Entre os trabalhos no campo das ciências sociais que se preocuparam detidamente com a prática da vaquejada, ver, por exemplo, Costa (2002), Barbosa (2006), Aires (2008), Menezes e Almeida (2008), Félix e Alencar (20II), Pereira (2016). Deles, Costa (2002), Aires (2008) e Pereira (2016) são as únicas abordagens antropológicas.

7 A partir de temáticas e eixos analíticos distintos, a relação de vaqueiros e "criadores" com os animais nos sertões tem sido abordada por Andriolli (20II), Teixeira (20I4), Vasques (20I6) e Pereira (20I6, 2017).

8 De modo geral, 'criadores' são pessoas que criam gado caprino, ovino, bovino ou equino na região. Entre os animais, as diferenças básicas consistem em quatro termos convencionais: 'criação' (rebanho de caprinos e ovinos), 'criatório de gado' (rebanho de gado bovino), 'animais' (sempre o gado equino) e 'criatório' (totalidade do rebanho de uma propriedade).

9 O conceito de "agenciamento coletivo" proposto por Deleuze e Guattari (2008) é interessante para avançar analiticamente no que se refere às relações do par vaqueirocavalo que compartilha territorialmente certas técnicas, signos e domínios em direção a um terceiro agente, o gado. No sentido conferido pelos autores, "agenciamento coletivo" é uma relação entre "formas de conteúdo" e "formas de expressão", um acoplamento entre uma materialidade específica e um regime de signos agenciados por humanos e não humanos.

\section{REFERÊNCIAS BIBLIOGRÁFICAS}

Aires, Francisco J. F. (2008). O espetáculo do cabra-macho: um estudo sobre os vaqueiros nas vaquejadas do Rio Grande do Norte, Natal-RN. Dissertação de Mestrado. PPGAS/UFRN. Andrade, Manoel Correia de. (I986) [1963]. A terra e o homem do Nordeste. 5 ed. São Paulo: Ed. Atlas. 
Andriolli, Carmen S. (20II). Sob as vestes do Sertão Veredas, O Gerais: "mexer com criação" no sertão do IBAMA. Tese de Doutorado. PPGCS/Universidade Estadual de Campinas.

Appadurai, Arjun. (I98I). The past as a scarce resource. Man, I6, p. 20I-2I9.

Barbosa, Eriosvaldo Lima. (2006). Valeu boi! O negócio da vaquejada. Teresina: Edufpi.

Barroso, Gustavo. (1930) [I9I2). Terra de sol: natureza e costumes do Norte. Rio de Janeiro: Francisco Alves.

Benjamin, Walter. (I987). O narrador: considerações sobre a obra de Nikolai Leskov. Obras escolhidas. Magia e técnica, arte e política. 3 ed. São Paulo: Brasiliense.

Bergson, Henri. (2009) [I9I9]. A energia espiritual. São Paulo: Ed. Martins Fontes.

Berliner, David C. (2005). The abuses of memory: reflexions on the memory boom in anthropology. Anthropological Quarterly, 78, p. I97-2II.

Bloch, Marc. (I925). Mémoire collective, tradition et coutume. À propos d'un livre récent. Revue de Synthèse Historique, 40 (nouvelle série I3)/II8-I20, p.73-83.

Cascudo, Luís da Câmara. (2005) [1939]. Vaqueiros e cantadores - folclore poético do sertão do Ceará, Paraíba, Rio Grande do Norte e Pernambuco. São Paulo: Edusp.

Cascudo, Luís da Câmara. (I956). Tradições populares da pecuária nordestina. Rio de Janeiro: Serviço de Informação Agrícola.

Cavignac, Julie A. (2009). Um mundo encantado: memória e oralidade no sertão do Rio Grande do Norte. In: Godoi, Emilia Pietrafiesa et al. (orgs.). Diversidade do campesinato: expressões e categorias. Construções identitárias e sociabilidades, v. I. São Paulo/Brasília: Unesp/Nead.

Collier Jr., John. (1973). Antropologia visual: a fotografia como método de pesquisa. São Paulo: Ed. Pedagógica e Universitária/Edusp.

Connerton, Paul. (I989). How societies remember. Cambridge/New York: Cambridge University Press.

Costa, Simone Pereira da. (2002). Rodeios e vaquejadas: o processo de construção de um novo esporte. Comuni- 
cação apresentada no GT Esporte, Política e Cultura, 26º Encontro Anual Anpocs, Caxambu (MG).

Deleuze, Gilles \& Guattari, Félix. (2012) [I980]. Mil platôs, v. 3. São Paulo: Ed. 34.

Deleuze, Gilles \& Guattari, Félix. (2008) [I980]. Mil platôs, v. 2. São Paulo: Ed. 34.

Détienne, Marcel \& Vernant, Jean-Pierre. (2008) [1974]. Métis - as astúcias da inteligência. São Paulo: Odysseus Editora.

Douglas, Mary. (I986). How institutions think. Syracuse: Syracuse University Press.

Fabian, Johannes. (2013) [1983]. O tempo e o outro. Como a antropologia estabelece seu objeto. Petrópolis: Vozes.

Felix, Francisco K. L. \& Alencar, Francisco A. Gomes de. (20II). O vaqueiro e a vaquejada: do trabalho nas fazendas de gado ao esporte nas cidades. Revista Geográfica da América Central, esp., p. I-I3.

Ferraz, Carla R. R. (2004). Quinca Pedro: o herói da caatinga. Floresta: [s.n.].

Furtado, Celso. (2007) [1959]. Formação econômica do Brasil. São Paulo: Companhia das Letras.

Godoi, Emília Pietrafesa. (I999). O trabalho da memória: cotidiano e história no sertão do Piauí. Campinas: Editora da Unicamp.

Halbwacks, Maurice. (I997) [I950]. La mémoire collective. Paris: Albin Michel.

Halbwacks, Maurice. (I994) [1925]. Les cadres sociaux de la mémoire. Paris: Editions Albin Michel.

Koury, Mauro Guilherme Pinheiro (org.). (200I). Imagem e memória: estudos em antropologia visual. Rio de Janeiro: Garamond.

Le Goff, Jacques. (2003) [1988]. História e memória. Campinas: Editora da Unicamp.

Lima, Roberto Cunha A. de. (2000). Um rio são muitos. Tempo Social - Revista de Sociologia da USP, I2/2, p. I47-I70. Lopes, Camilo Antônio Silva. (20I6). Vaqueiros, seleiros, carreiros e trançadores: uma etnografia com coisas, pessoas e signos. Tese de Doutorado. PPGCS/Universidade Estadual de Campinas. 
Marques, Ana Claudia D. R. (2013). Founders, ancestors and enemies. Memory, family, time and space in the Pernambuco Sertão. Journal of the Royal Anthropological Institute, I9/4, p. 716-733.

Marques, Ana Claudia D. R. (2002). Intrigas e questões: vingança de família e tramas sociais no sertão de Pernambuco. Rio de Janeiro: Relume-Dumará/Núcleo de Antropologia da Política UFRJ.

Medrado, Joana. (2012). Terra de vaqueiros: relações de trabalho e cultura política no sertão da Bahia, I880-I900. Campinas: Editora da Unicamp.

Mello, Frederico P. de. (20II). Guerreiros do sol: violência e banditismo no Nordeste brasileiro. São Paulo: A Girafa.

Menezes, Djacir. (I970) [I937]. O outro Nordeste. Rio de Janeiro: Artenova.

Menezes, Sônia S. M. \& Almeida, Maria Geralda de. (2008). Vaquejada: a pega de boi na caatinga resiste no sertão sergipano. Vivência, 34, p. I8I-I93.

Nora, Pierre. (1989). Between memory and history: les lieux de mémoire. Representations, 26, p. 7-24.

Pereira, Renan Martins. (2017). Rastros e memórias. Etnografia dos vaqueiros do sertão (Floresta-PE). Dissertação de Mestrado. PPGAS/Universidade Federal de São Carlos.

Pereira, Renan Martins. (20I6). Dominação e confiança: vaqueiros e animais nas pegas de boi do sertão de Pernambuco. Teoria e Cultura, II, p. 63-80.

Pollak, Michael. (I989). Memória, esquecimento e silêncio. Estudos Históricos, 3, p. 3-I5.

Prado Junior, Caio. (2006) [1945]. História econômica do Brasil. São Paulo: Brasiliense.

Ricoeur, Paul. (2000). La mémoire, l'histoire, l'oubli. Paris: Seuil.

Rouch, Jean. (2003) [1975]. The camera and man. In: Hockings, Paul. Principles of visual anthropology. Berlin/New York: Ed. Walter de Gruyter.

Sena, Custódia S. (20II). Uma narrativa mítica do sertão. Revista Avá, 2, p. 55-75. 
Sena, Custódia S. (1998). A categoria sertão: um exercício de imaginação antropológica. Sociedade e Cultura, I/I, p. I9-28.

Severi, Carlo. (2010). El sendero y la voz. Una antropología de la memoria. Buenos Aires: SB.

Sztutman, Renato. (2005). Imagens perigosas: a possessão e a gênese do cinema de Jean Rouch. Cadernos de Campo, I3/I3, p. II5-I24.

Teixeira, Jorge Luan Rodrigues. (2014). Na terra dos outros: mobilidade, trabalho e parentesco entre os moradores do Sertão dos Inhamuns (CE). Dissertação de Mestrado. PPGAS/Universidade Federal do Rio de Janeiro.

Vasques, Ariane. (20I6). As veredas do bode. Criação na solta e laboro no sertão de Pernambuco. Dissertação de Mestrado. PPGAS/Universidade Federal de São Carlos.

Vernant, Jean-Pierre. (1978). A bela morte e o cadáver ultrajado. Discurso, 9. p. 3I-62.

Villela, Jorge Mattar. (2008a). O povo em armas: violência e política no sertão de Pernambuco. Rio de Janeiro: Relume Dumará.

Villela, Jorge Mattar. (2008b). Política e eleições no sertão de Pernambuco. O povo em armas. Fortaleza: Pontes Editora. 


\section{VELEJAR E DESCOBRIR: CONSIDERAÇÕES SOBRE VAQUEIROS, CORPOS E LEMBRANÇAS}

\begin{abstract}
Resumo
Neste artigo, meu objetivo é analisar a produção de 'prestígio', reputação e memória entre vaqueiros do sertão de Pernambuco a partir de suas relações com o corpo, os animais e o território. Para tanto, demonstro que a exaltação de uma vida de sacrifícios e as tarefas concernentes ao ofício do vaqueiro resultam de diversas de suas práticas e de seus conhecimentos, mas também de sua habilidade retórica de narrar e reconstruir acontecimentos passados. Nas práticas denominadas 'pega de boi', vaqueiros, animais e caatingas surgem como seres em disputa, buscando triunfar uns em relação aos outros. Para analisar essas práticas, o material etnográfico ao qual recorro são narrativas de um 'vaqueiro velho' cuja particularidade no modo de confeccionar oralmente as suas experiências passadas expressa de uma só vez a importância do corpo, da memória e dos animais no cotidiano dos vaqueiros.
\end{abstract}

\section{SAILING AND DISCOVERING: CONSIDERATIONS ABOUT COWBOYS, BODIES AND MEMORIES} a life of sacrifice and the tasks concerning the cowboy's craft result from several of his practices and knowledges, but also from his rhetorical ability to narrate and to reconstruct past events. In the practices known as pegas de boi, cowboys, animals and the native vegetation (caatinga) appear as beings in dispute, seeking to triumph over each other. In order to analyze these practices, the ethnographic material to which I refer are narratives of an old cowboy whose particularity in the way of making orally his past experiences expresses at once the importance of body, memory and animals in the daily life of the cowboys.
Palavras-chave

Vaqueiro; narrativa; corpo; memória; animais.
Keywords

Cowboy; narrative; body; memory; animals. 